\title{
Effect of Matrix Metalloproteinase-9 Knockout on Vein Graft Remodelling in Mice
}

\author{
Anita C. Thomas ${ }^{a, b}$ Andrew C. Newby ${ }^{a}$ \\ ${ }^{a}$ Bristol Heart Institute, University of Bristol, Bristol, UK; ${ }^{b}$ Australian Institute for Bioengineering and \\ Nanotechnology, The University of Queensland, Brisbane, Qld., Australia
}

\section{Key Words}

Matrix metalloproteinases - Vein graft • MMP-9 • MMP-2 •

Remodelling

\begin{abstract}
Long-term success in vein grafting for bypassing arteries blocked by atherosclerosis is limited by migration and proliferation of smooth muscle cells to form a neointima. Matrix metalloproteinases (MMPs), in particular MMP-2 and MMP-9, are implicated in neointimal formation by freeing smooth muscle cells from the cell-matrix contacts that normally restrict migration. We investigated the role of MMP-9 in vein grafts directly, using knockout mice. Vein grafts in MMP-9-1and wild-type mice had similar luminal and graft areas at 1 , 4 and 8 weeks after engraftment, increasing with time. There was a relationship between the perimeter of the external elastic lamina and graft thickness (indicating graft remodelling) in $\mathrm{MMP}^{-9^{-/}}$mice at 1 week after surgery not apparent in control mice until later $\left(r^{2}=0.933\right.$ for MMP- $9^{-/-}$mice, $r^{2}=$ 0.040 for wild-type mice). Grafts in MMP-9-/- mice had 6 -fold more pro- and active MMP-2 $(p=0.013, p=0.026)$ than grafts in wild-type mice. Grafts from MMP-9-/- mice also had more collagen ( $p=0.046$ at 8 weeks), without any difference in cell number. Thus, while a lack of MMP-9 did not alter vein graft wall area or cellularity, grafts from $\mathrm{MMP}^{-9^{-/}}$mice accumu-
\end{abstract}

lated more collagen and had earlier linear expansive remodelling, possibly due to an early compensatory increase in MMP-2.

Copyright $\odot 2009$ S. Karger AG, Basel

\section{Introduction}

Autologous vein grafting is widely used to bypass regions of coronary and peripheral arteries blocked by atherosclerotic plaques. Vein graft intimal thickening and remodelling occurs as an adaptation to increased wall tension and arterial flow, with up to $15 \%$ of grafts stenosing within the first year as a result of thrombosis, neointima formation and atherosclerosis [1]. More become obstructed each year, so that by 10 years after surgery $40 \%$ of grafts are completely blocked and a further $30 \%$ have compromised flow [1]. As a result, symptoms frequently reoccur and repeat surgery and corrective angioplasty is increasingly practiced, occasioning significant morbidity and increased cost.

Acute thrombosis in vein grafts is caused by surgical trauma, mechanical stress and vessel wall cell damage or loss, occurring with even the most careful handling $[1,2]$. The components of resident (organized) thrombus contribute to the developing neointimal thickening in both 
vein grafts and arteries, either by becoming absorbed into the vessel wall and developing smooth muscle-like characteristics or by contributing factors (including platelet-derived growth factor) that stimulate vascular smooth muscle cells (VSMC) to proliferate and produce matrix, thus promoting the longer-term complications of vein graft disease, neointimal thickening and atherosclerosis [1-4]. However, growth factors acting on intact blood vessels do not by themselves cause VSMC migration or proliferation. Matrix remodelling by extracellular proteases, including plasminogen activators, heparanases and matrix metalloproteinases (MMPs) is also required [4-9].

The MMP family consists of at least 23 proteases, 14 of which have been demonstrated in blood vessels [4]. The precise identity of the MMPs involved in vein graft neointima formation is not known, but there is much evidence implicating the gelatinases MMP-2 and MMP-9, also known as the basement membrane-degrading MMPs, because their substrates include collagen, elastin, laminin and core proteins of heparan sulphate proteoglycans $[4,10]$. Since each VSMC is surrounded by a basement membrane, remodelling of this structure is thought most important for cell-matrix interactions.

MMPs not only directly and precisely cleave the matrix to release bioactive matrix fragments, they also have additional actions, such as activating or releasing sequestered growth factors, activation of other MMPs and proteases, or disrupting cell to cell contacts $[4,9]$. While there is considerable functional overlap between the different MMPs, MMP-9 is known to release matrix fragments that influence angiogenesis and tumour growth and liberate vascular endothelial growth factor and transforming growth factor- $\beta[4,9]$. As MMP-9 degrades inflammatory cytokines (such as interleukin-1 $\beta$ ) and promotes production of interleukin-10 (associated with a less inflammatory profile) [10-12], a lack of MMP-9 would affect the local inflammatory environment. MMP-9 is also associated with increased vascularisation and ossification of growth plates [11].

Little is known about the specific role of gelatinases in vein grafts. While MMP-2 and MMP-9 are either absent or present at low levels in normal vein, their expression becomes elevated, and possibly activated, soon after engraftment. This may be a response to preparative injury or exposure to the arterial environment. There is rapid up-regulation of MMP-9 in particular, but other MMPs, including the interstitial collagenase MMP-1 and stromelysin (MMP-3), are less drastically up-regulated $[8,13-$ 17]. Vein grafts given additional tissue inhibitor of metal- loproteinase (TIMP)-2 (which reduces both MMP-2 and MMP-9 activity) are known to have smaller neointimal lesions and a reduced graft diameter, due to vessel remodelling [18]. Normal arteries from MMP-9 null mice express less MMP- 2 than those in control mice, and have a reduced neointimal cell density after de-endothelialisation or ligation [19-21]. Hence, it has been proposed that MMP-2 and MMP-9 play an important role in neointima formation.

In this study we investigated the role of MMP-9 in vein graft neointima formation directly using MMP-9 null mice, testing the hypothesis that the MMP-9 null mice have altered vein graft thickening and collagen deposition compared with wild-type mice.

\section{Methods}

Vein Graft Surgery

All animals were used under licences obtained from the UK Home Office and the Guide for the Care and Use of Laboratory Animals [also known as Principles of Laboratory Animal Care, NIH publication No. 86-23, revised 1985, 1996 (www.nap.edu/ catalog/5140.html)] was followed. A total of $96{\mathrm{MMP}-9^{-/} \text {mice as }}^{-1}$ well as age- and background-matched wild-type mice were used in these studies, bred on a 129/C57 background at the University of Bristol animal house, from homozygous (not heterozygous) parents. Heterozygotes were not used in these studies, as it is not known if heterozygotes are functionally impaired in terms of MMP-9 expression and/or activity. We used female donated grafts in male recipients, to maximise the use of the MMP-9 null mice. The MMP-9 null mice were originally obtained from Dr. S. Shapiro, Harvard Medical School, Boston, USA [11]. The mice received food and water ad libitum.

The vein grafting procedure was essentially that of Zou and colleagues $[2,18,22]$. Donor female mice were anaesthetised, heparinised, and the thoracic vena cava carefully cleaned of adherent fat and harvested. Age- and genotype-matched male mice were anaesthetised and had their right carotid arteries mobilized, without heparinisation. Blood flow in the artery was halted using surgical microclips, the artery ligated, and the ends of the arteries everted over nylon cuffs and tied in place. After both ends of the cuffed arteries were checked for visible clots, the vein graft was placed carefully over the cuffs, secured, and blood flow re-established. The surgery was considered successful if blood flow and a pulse were observed within the graft (assessed visually). Time taken until wound closure was approximately $20 \mathrm{~min}$. Tail tips were taken from both donor and recipient at the time of surgery, to confirm that the mice had been bred from the appropriate homozygous parents.

\section{Graft Harvest and Histology}

At 1, 4 or 8 weeks after surgery the mice were anaesthetised, the graft isolated, and the presence of a pulse and blood flow through the graft established (assessed visually). The grafts were removed and rinsed in phosphate buffered saline (PBS) for later zymography (at 1 week only: $\mathrm{n}=7$ /group), or left in place for per- 
fusion fixation ( $\mathrm{n}=10-14$ /group). The grafts were post-fixed in $4 \%$ formaldehyde, then processed and embedded in paraffin as previously described [22]. 5- $\mu \mathrm{m}$ sections were cut, and stained with haematoxylin and eosin (HE) or Miller's elastin/van Gieson stain (EVG) for histological evaluation and computer-assisted morphometry (ImagePro Plus; Media Cybernetics, Silver Spring, Md., USA).

We performed quantitative image analysis on at least 2 nonconsecutive EVG-stained sections/graft, to determine the graft perimeter [external elastic lamina (EEL) length], luminal and graft thickness, and luminal and total graft areas (the area between the lumen and the adventitia). The neointima and media were not measured separately, as there are only 1-2 layers of cells in the media of the mouse vein [22]. For an indication of graft cellularity, the number of nuclei in 4 quadrant $(100 \times$ magnification) views/section, 2 non-consecutive HE-stained sections/graft was counted. The incidence of thrombus formation (as identified macroscopically, or in micrographs stained using $\mathrm{HE}$ [for the presence of erythrocytes (orange-red) and fibrin (deep pink)] and graft rupture were also noted. Any grafts that were occluded or had poor flow at time of harvest were not used for further analysis (methodology as in previous studies using this model) [Dr. Yanhua $\mathrm{Hu}$, pers. commun.].

Sections neighbouring the EVG-stained sections were stained for collagen using Picrosirius red. Sections were stained in $0.1 \%$ Sirius red in aqueous saturated picric acid, de-stained in $0.01 \mathrm{~N}$ $\mathrm{HCl}$, dried, cleared and mounted. Five to ten vein grafts were examined in each group, using ImagePro Plus to measure the area of collagen (Picrosirius red staining) within the vein graft. Adventitial collagen was not included because the amount of adventitia remaining after harvesting and the degree of adventitial injury during dissection could not be controlled. In addition, the boundary between pre-existing donor and newly developed recipient adventitial tissue was indistinct. The area of the vein grafts was measured under white light (and found to be the same as in EVG-stained sections). The area of Picrosirius red staining under circularly polarised light maximised for birefringence intensity (that is, the area of collagen content) was measured (non-dark channel isolated and threshold analysis applied). Under these conditions, green or yellow strands indicate thin or recently deposited collagen, while red strands indicate thick (old) collagen $[23,24]$.

\section{Gelatin Zymography}

Grafts were harvested from mice, rinsed in PBS and immediately frozen in liquid nitrogen. Each graft $(2-10 \mathrm{mg})$ was chopped into small pieces in the presence of $50-100 \mu \mathrm{l}$ SDS lysis buffer. The samples were centrifuged and the supernatant assayed for protein concentration (BCA assay; Pierce). 7.5\% SDS gels containing $2 \mathrm{mg} / \mathrm{ml}$ gelatin were prepared and each lane loaded with sufficient protein $(4 \mu \mathrm{g})$ to yield bands within a linear measurement range for MMP-2 [14]. Conditioned medium from stimulated HT1080 cells was used as a gel marker for MMP-2 and MMP-9 [14] as well as ligated arteries from wild-type mice as positive controls. Gels were run in the cold at approximately $70 \mathrm{~V}$, and at completion the SDS was removed from the gel using 2.5\% Triton-X exchange buffer. To identify bands indicating gelatinase activity requiring metal ions, replicate gels were incubated overnight in $0.1 \%$ Triton-X incubation buffer in the presence or absence of either 20 mM EDTA (a metal ion chelator) or $200 \mu \mathrm{M} 1,10$ phenan- throline (a zinc chelator) $[5,10,14]$. Gelatinolytic activity was determined after staining with Coomassie Brilliant Blue R250. A densitometer (GelDoc 1000; BioRad) was used to measure the cleared areas after destaining, using the Quantity One program from BioRad.

\section{Statistical Analysis}

Mouse weights were compared using Student's t test after normality was checked using the Shapiro-Francia test. Graft patency and thrombosis data were compared using Fisher's exact test. Statistical calculations on the graft and luminal areas were performed on square root-transformed data after normality was checked and outliers removed. Data were subjected to regression analysis and examined for the effects of time (1, 4 or 8 weeks) and mouse strain (grafts from wild-type or MMP-9 null mice). The (untransformed) EEL perimeter and nuclei number data were subjected to regression analysis for the effect of time and mouse strain, after normality was checked and any outliers removed (Grubbs' test). Vein grafts were examined for a correlation between EEL perimeter and graft or luminal thickness (after outliers were removed). A correlation of 0.7 or above was considered strong. Collagen content (in Picrosirius red-stained sections) was logarithmically transformed, subjected to regression analysis for the effect of time and mouse strain, after normality was checked (Shapiro-Francia test), and outliers removed. Band densitometry data obtained from gelatin zymograms were compared using a 1-way ANOVA and tests for equal variances (Bartlett's test) and a two-sample Wilcoxon rank-sum (Mann-Whitney) test. The logarithmically transformed data were finally compared using a twosample t test with equal variances. No outliers were found. The data were back-transformed (if necessary) and are presented as mean and standard deviation (SD), with differences indicated by $95 \%$ confidence intervals (CI). These statistical analyses were performed under the guidance of statistician Dr. Chris Rogers at the Bristol Heart Institute. The Stata Statistical Software, release 9 (StataCorp), SigmaStat (Jandel Scientific) and InStat 3.05 (GraphPad Software Inc.) packages were used.

\section{Results}

\section{MMP-9 Does Not Influence Graft Patency and Thrombosis}

As reported previously [11], the MMP-9 null mice were smaller than age-matched wild-type mice $(24.4 \pm 2.9 \mathrm{~g}$ MMP-9 $^{-/-}, 30.6 \pm 2.5$ g wild type; $\left.\mathrm{p}<0.0001\right)$. Two graft ruptures were observed (at 5 and 7.5 weeks, 1 in each strain), which resulted in immediate death. Three grafts from either strain had old, recannalised thrombi with excellent flow; these grafts were removed from the study. There was an overall thrombus rate of $12.1 \%$ in MMP-9 null mice and $12.9 \%$ in wild-type mice observed $(\mathrm{p}=0.35$, no significant difference at any time point), a level similar to that found previously in this model (approx. 10\%) [Dr. Yanhua Hu, pers. commun.], leaving 8-12 animals/ group. 
Fig. 1. Comparison of vein grafts from MMP-9 null $(\diamond)$ and wild-type ( $\boldsymbol{\square})$ mice. a Luminal area; b graft area; $\mathbf{c}$ graft cellularity; d EEL perimeter. Data are presented as means $\pm \mathrm{SD}$. There was no significant difference between grafts in MMP-9 null and wild-type mice.

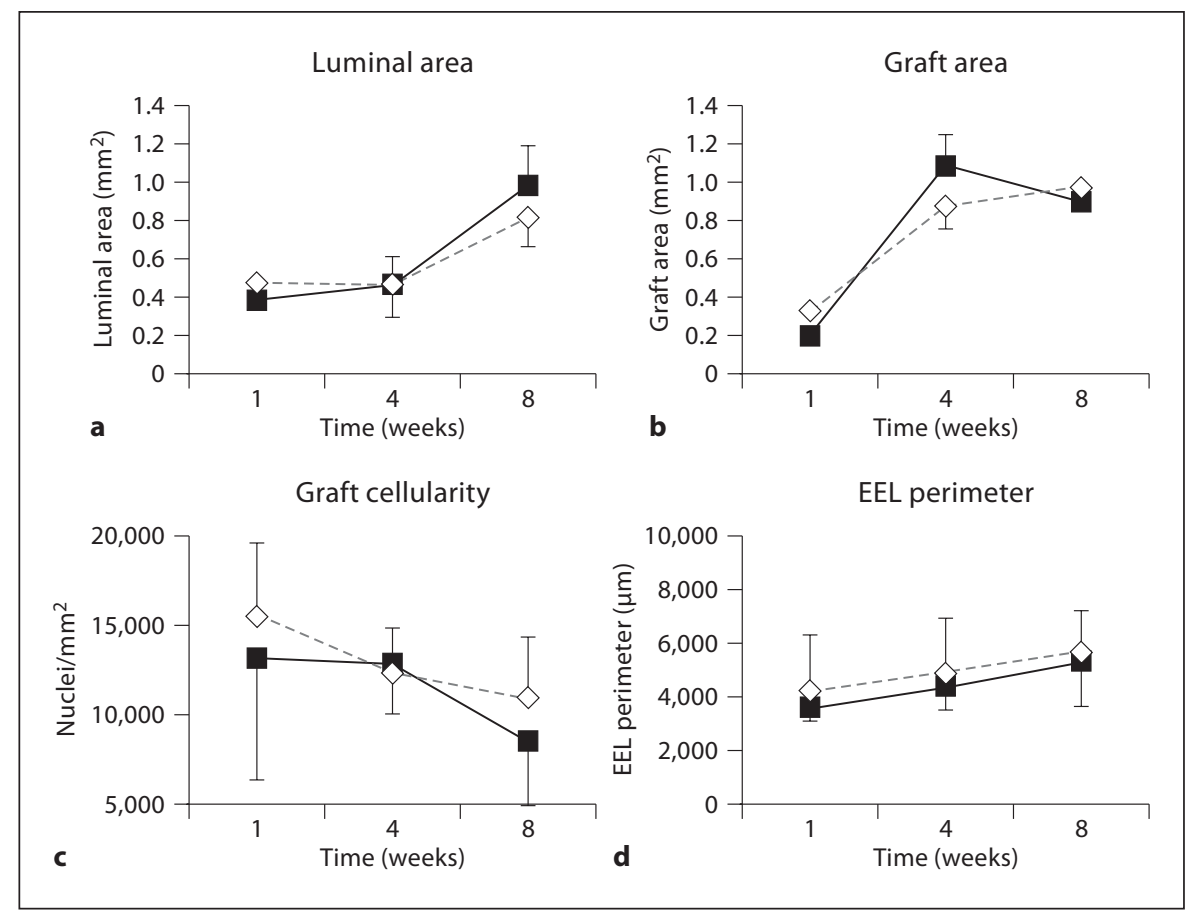

MMP-9 Does Not Affect Luminal or Graft Area

There was no difference in graft luminal area between the MMP-9 ${ }^{-/-}$and control mice (fig. 1a; $\mathrm{p}=0.38$ ). Luminal area in both strains of mice increased with time ( $\mathrm{p}=$ 0.029 ), with a $50 \%$ increase between 4 and 8 weeks. There was no interaction between time and mouse strain.

While there was no difference in the wild-type and MMP-9 null mice graft area (that is, the area between the lumen and the adventitia, fig. $1 b ; p=0.70)$, there was a 3 - to 4-fold increase in graft area with time ( $\mathrm{p}<0.0001$; 1 week $95 \%$ CI $0.176-0.359 \mathrm{~mm}^{2}$, 4 weeks $95 \%$ CI $0.647-$ $1.376 \mathrm{~mm}^{2}$, 8 weeks $95 \%$ CI $0.661-1.147 \mathrm{~mm}^{2}$ ). There was no interaction between time and strain.

\section{MMP-9 Does Not Alter Cellularity}

Grafts in both wild-type and knockout mice had fewer nuclei $/ \mathrm{mm}^{2}$ with time after engraftment (fig. 1c; $\mathrm{p}=$ $0.006)$, but there was no difference in cell density between the 2 strains of mice $(\mathrm{p}=0.31)$.

\section{MMP-9 Influences Expansive Remodelling}

The perimeter of the EEL was similar in both groups of mice ( $\mathrm{p}=0.15$; fig. $1 \mathrm{~d}$ ), both strains increasing with time ( $\mathrm{p}=0.25$ in MMP-9 ${ }^{-/}$grafts, $\mathrm{p}=0.021$ in control grafts). According to this parameter, therefore, there was no difference in expansive remodelling between
MMP-9-/- and wild-type mice. However, expansive remodelling can also be defined as an increase in EEL perimeter to accommodate an increased neointima. In this case a positive relationship between EEL perimeter and vessel thickness is expected [24]. While early grafts in wild-type mice had no such relationship (the slope was not significantly different from zero, $p=0.64$ ), there was a strong correlation between the graft thickness and EEL perimeter in MMP-9-1- mice at 1 week [fig. 2a (1 week) $r^{2}=0.933$ for MMP- $9^{-/-}$mice, $r^{2}=0.040$ for wild-type mice]. At 4 and 8 weeks after surgery, both strains of mice had a good correlation between the graft thickness and EEL perimeter [fig. $2 \mathrm{c}$ (4 weeks), $\mathrm{r}^{2}=0.744$ for MMP- $9^{-/-}$ mice, $r^{2}=0.676$ wild-type mice; fig. 2e ( 8 weeks), $r^{2}=$ 0.630 for MMP- $9^{-/-}$mice, $r^{2}=0.771$ for wild-type mice].

Similarly, the grafts from wild-type mice had a delayed response in remodelling of the lumen compared with grafts from MMP-9 mice (as determined by the correlation between EEL perimeter and luminal thickness; fig. $2 b, d, f)$. Only grafts from wild-type mice examined at 8 weeks had a moderately good correlation (1 week $r^{2}=0.424,4$ weeks $r^{2}=0.181,8$ weeks $r^{2}=0.604$ ), but there was a trend for the data at this time point to depart from linearity $(p=0.07)$. This was not due to the presence of outliers (which were identified and removed during the statistical analysis). Grafts in MMP-9 null mice had a 


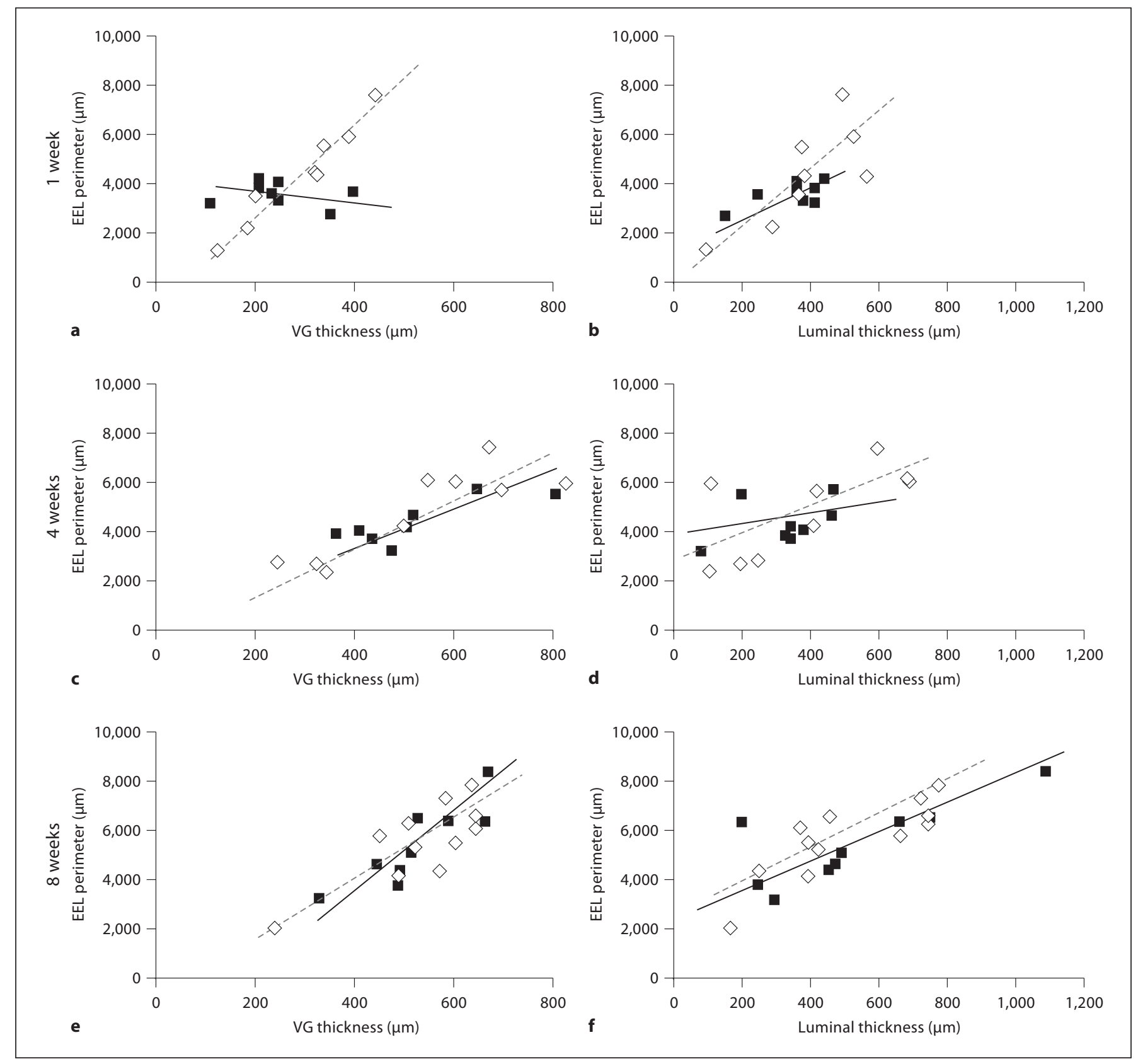

Fig. 2. Remodelling in vein grafts (VG) from MMP-9 null $(\diamond)$ and wild-type ( $\boldsymbol{\square})$ mice. Remodelling is given as EEL perimeter versus graft thickness at 1 (a), 4 (c) and 8 (e) weeks after grafting, or the EEL perimeter versus luminal thickness at 1 (b), 4 (d) and 8 (f) weeks after grafting.

good correlation at 1 and 8 weeks, with data at 4 weeks being more widely spread ( 1 week $\mathrm{r}^{2}=0.604$, 4 weeks $r^{2}=0.474,8$ weeks $\left.r^{2}=0.688\right)$. The results imply an early increased capacity for compensatory remodelling in MMP- $9^{-/-}$mice not apparent in wild-type mice until later time points.
Collagen Content Is Increased in Grafts from MMP-9 Null Mice

The pattern of collagen staining in both wild-type and MMP- $9^{-/-}$mice was similar at all time points. At 1 week there was little collagen staining near the lumen and, when present, it was newly formed (consisting of thin yel-

J Vasc Res 2010;47:299-308 

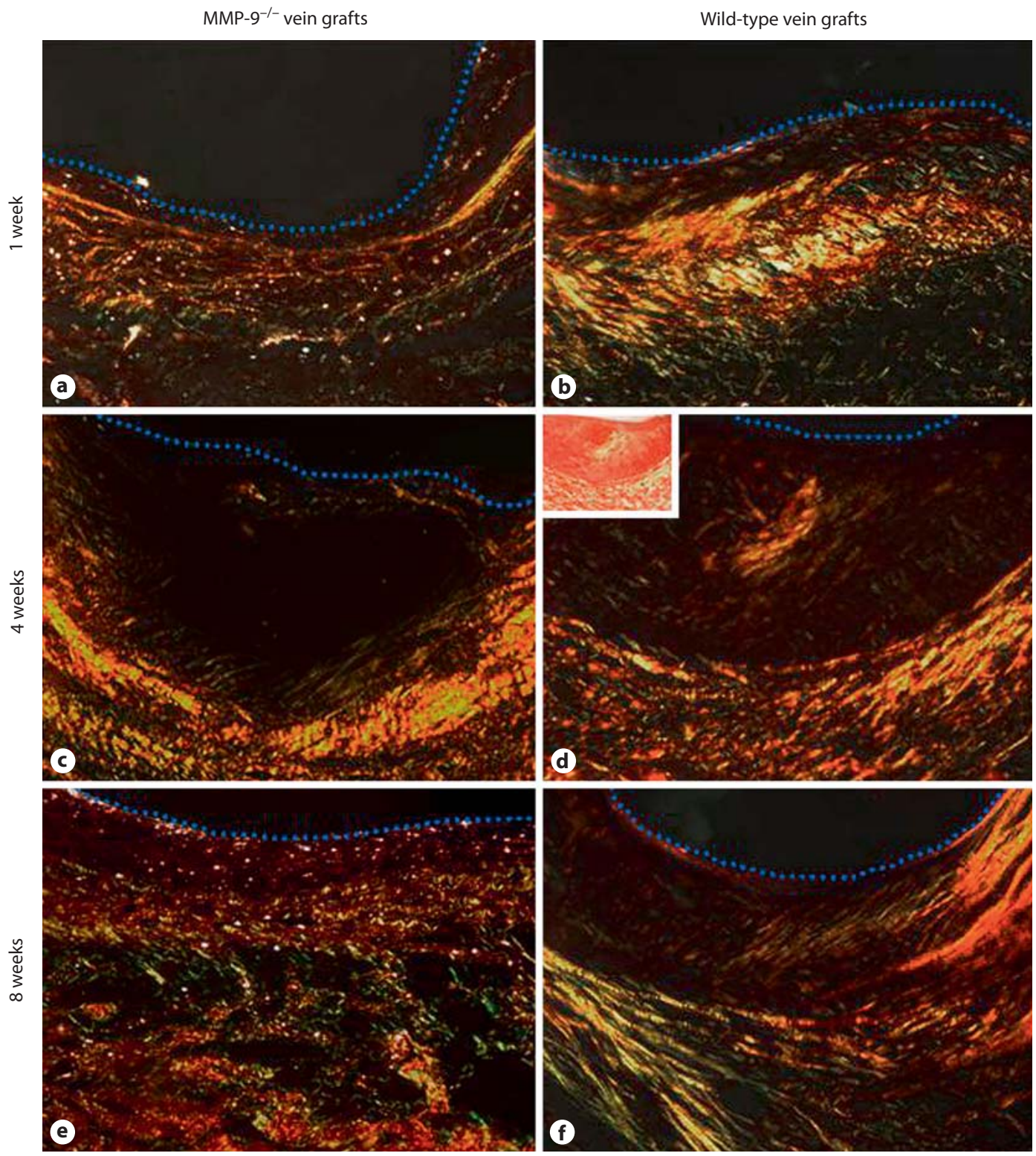

Fig. 3. Collagen deposition in vein grafts. Under white light (inserted micrograph) the levels of Picrosirius red-stained collagen cannot be accurately quantified, but when observed using polarised light (darkfield micrographs) the levels of recently deposited (thin green and yellow strands) and older collagen (thicker, red strands) can be quantified. a MMP- $9^{-/-}$vein graft at 1 week; $\mathbf{b}$ wild-type vein graft at 1 week; c MMP-9-1- vein graft at 4 weeks; $\mathbf{d}$ wild-type vein graft at 4 weeks; e MMP-9-/- vein graft at 8 weeks; $\mathbf{f}$ wild-type vein graft at 8 weeks. A dotted blue line indicates the lumen. $\times 200$. g Collagen content of vein grafts from MMP-9 null $(\diamond)$ and wild-type $(\square)$ mice. Data are presented as means \pm SD. ${ }^{*} \mathrm{p}<0.05$.

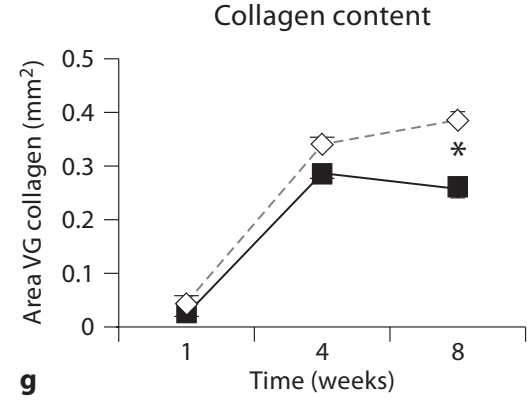


low strands; fig. 3a, b). The outer region of the graft had red, green and yellow staining, indicating that there was new collagen being deposited beside older collagen. There was only a limited amount of recently deposited collagen in the adventitia of grafts, perhaps because the part of the adventitia was uninjured tissue carried over from the donor veins. Indeed, the boundary between graft and recipient adventitial tissue was not clear at any time point, and so we did not try to measure or interpret adventitial collagen deposition further. At 4 weeks, most grafts still had weak staining near the lumen, with some areas of red (older) collagen (fig. 3c, d). The outer graft wall had red and yellow staining, with some new (green) areas. By 8 weeks there was more obvious collagen staining, with green, yellow and red areas in both inner and outer areas (fig. 3e, f), but the area of collagen nearest the lumen was often layered at an angle to that in the outer graft wall (fig. 3f). Adventitial collagen was present in all grafts by this time.

As expected, grafts in both wild-type and knockout mice had more collagen with time after engraftment (fig. 3g; $\mathrm{p}<0.001$ ). Overall, MMP-9 null vein grafts had 1.5 -fold more collagen than control grafts $(\mathrm{p}=0.002$, $95 \%$ CI of the difference $0.120-0.202 \mathrm{~mm}^{2}$ ). Grafts in MMP- $9^{-/-}$mice at 8 weeks had significantly more collagen than grafts in control mice $(\mathrm{p}=0.046)$.

\section{Grafts from MMP-9 Null Mice Have More MMP-2}

MMP-2 and MMP-9 levels in grafts from MMP-9-1and wild-type mice were compared in grafts at 1 week after engraftment, using gelatin zymography. Samples of freshly harvested vena cava (from either strain) had similar levels of MMP-2 in gels loaded with $>20 \mu \mathrm{g}$ protein/ lane, but no MMP-9 or active MMP-2 bands were observed. These bands cannot be seen in figure $4 \mathrm{a}$, as only $4 \mu \mathrm{g}$ protein were loaded in each lane in these gels (so that vein grafts yielded MMP-2 bands within the linear range of the densitometer). Vein grafts from control animals contained MMP-9 (not active MMP-9) and, as expected, there was no MMP-9 in grafts from MMP-9 null mice (fig. 4a). There was not enough tissue available to perform Western blots (each graft weighted only 2-10 mg), but the band was confirmed as MMP-9 in Western blots of the ligated artery (positive control) samples [A. Gill, pers. commun.). The cleared areas equating to MMP-2 and MMP-9 in the vein grafts were eliminated by phenanthroline (a zinc chelator; fig. 4b) and EDTA (a metal ion chelator; fig. 4c). This indicated that the bands were gelatinases requiring divalent cations for activity, and thus likely to be MMPs.

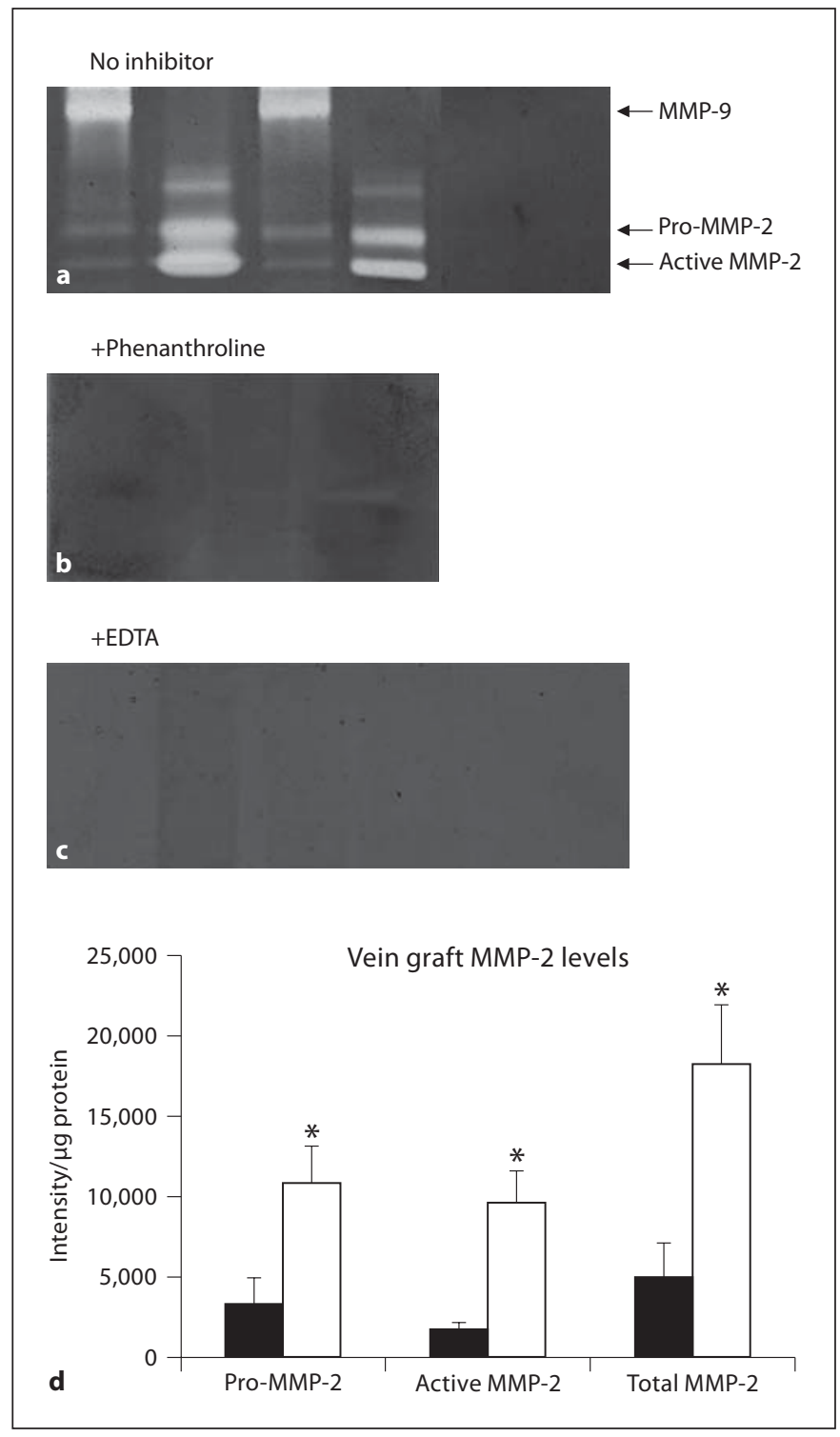

Fig. 4. Freshly harvested vena cavae and vein graft extracts from different MMP-9 null ( $\square$ ) and wild-type ( $\square$ mice were compared using gelatin zymography. Triplicate gels were loaded with vein grafts harvested 1 week after engraftment (wild-type grafts lanes 1,3, MMP-9 null vein grafts lanes 2,4) or extracts of freshly harvested vena cavae from wild-type (lane 5) and MMP-9 null mice (lane 6) and incubated in the presence of no inhibitor (a) or the MMP inhibitors phenanthroline (1 week grafts only; b) or EDTA (c). d Pro, active and total MMP-2 levels in the vein grafts. Data are presented as means \pm SD. ${ }^{*} \mathrm{p}<0.05$. 
Grafts from MMP-9 ${ }^{-/-}$mice had 5.5- to 6.1-fold more pro, active and total MMP-2 than grafts from wild-type mice (fig. $4 \mathrm{~d}$; pro MMP-2 $\mathrm{p}=0.013$, active MMP- $2 \mathrm{p}=$ 0.026 , total MMP-2 $p=0.004)$. Several minor gelatinolytic bands were evident in vein graft extracts, but there was considerable individual variation and the band intensities were not significantly different between the 2 strains of mice (Student's t test, $\mathrm{p}=0.32-0.35$ ). These bands were also eliminated by EDTA or phenanthroline, suggesting that they too resulted from MMP activity.

\section{Discussion}

We examined the influence of MMP-9 deletion on veins grafted into the mouse carotid artery, and found that thrombus formation, cellularity as well as the changes in luminal and graft areas were similar in MMP-9 ${ }^{-/}$ and wild-type mice. A linear relationship in graft remodelling was observed in the MMP-9 ${ }^{-/}$grafts at 1 week, earlier than in wild-type mice, and by 8 weeks after grafting there was a significant increase in collagen content in the MMP-9-/- grafts not observed in the wild-type grafts. This may be at least partially explained by our finding that MMP-9-/- mice had greatly increased MMP-2 levels at 1 week compared with grafts from wild-type mice.

\section{Role of MMP-9 in Vein Graft Thrombosis}

It has been reported that all mouse vein grafts develop microthrombi within $24 \mathrm{~h}$ of surgery, and many grafts are completely thrombosed; some remain thrombosed at harvest (2-16 weeks later) [2, 22]. We found that by 1 week after engraftment, approximately $12 \%$ of grafts had attached thrombi, and that thrombosed and occluded grafts (in either group) were recannalised. This is an important functional phenomenon, because it ensures that circulation is re-established in the graft after a thrombotic event. As MMPs are involved in the activation of components of the coagulation cascade and fibrinolysis, as well as these enzymes in MMP activation $[4,6,7,19]$, it is possible that the expression of MMPs might play a role in this vein graft thrombosis. For example, MMP-9 overexpression in porcine vein grafts leads to increased thrombus formation within injured arteries [7], and fibrin is known to be a substrate for MMP-9 [10]. We have previously shown that fibrin is deposited on arteries within $10 \mathrm{~min}$ of damage (before any neointimal formation) [3], and thus it is probable that thrombus formation is similarly associated with vein graft thickening [2]. This gives a possible sequence of events in vein graft thrombosis and atherosclerosis as (1) coagulation cascade activation and thrombus formation, overlapping with (2) MMP activation and matrix mobilization, followed by (3) cell proliferation/migration and neointimal formation.

\section{Role of MMP-9 in Vein Graft Thickening}

We proposed that MMP-9 null mice would have reduced vein graft thickening and fewer cells, but our results did not support this hypothesis. We found that vein grafts from MMP-9-/- mice had no difference in luminal or graft area or graft cell density compared with grafts in wild-type mice, although luminal and graft area and EEL perimeter increased with time and nuclei number decreased with time after engraftment in both strains of mice. This is similar to the changes that have been reported in vein grafts in rabbits [17], and is similar to 8 week mouse vein graft area reported by other researchers [2]. However, the graft thickness was double that found previously [22]. The most likely explanation for the lack of effect specific to MMP-9 null mice was the compensatory up-regulation of MMP-2 we found.

\section{Role of MMP-9 in Collagen Content and Graft \\ Remodelling}

MMPs acting in concert can completely degrade collagen and other components of extracellular matrix, resulting in structural weaknesses within the vessel. Knowing this, we thought that a loss of MMP-9 would lead to increased levels of collagen within the vein graft, and our results confirm this hypothesis (similar to the situation in ligated arteries [24], but not in areas of myocardial infarction [23]).

We found that there was a positive correlation in remodelling (a linear relationship in graft remodelling) from 1 week after engraftment in the MMP- $9^{-/-}$mice, only found at later times in grafts in wild-type mice. This was most evident when the influence of vein graft thickness was analysed, but was also apparent when luminal thickness was examined. It was not associated with any change in EEL perimeter. Thus, graft and luminal thickness are good predictors of the EEL perimeter in vein grafts from MMP-9 null mice from the earliest time point examined, but there was no correlation until later times in grafts from wild-type mice. This difference in geometrical remodelling was not due to change in collagen deposition/destruction or cellularity (as these were the same in vein grafts in both groups of mice at 1 and 4 weeks), but may be due to the large increase in pro and active MMP-2 in grafts from MMP-9 null mice. This change in MMP-2 expression has been reported previously in areas 
of myocardial infarction in MMP- $9^{-/-}$mice [23], but was not found in ligated arteries in MMP-9 null or ApoE/ MMP-9 double knockout mice [24, 25]. We also found that other compounds with gelatinase activity were present, as found in infarcted hearts in MMP- $9^{-/-}$mice [23]. We have not identified if the additional MMP-2 in the MMP-9 null mice is available for use - it may be bound by integrins, proteoglycans, TIMP-2 and other molecules.

\section{Why Is MMP-2 Elevated in Vein Grafts from MMP-9}

Null Mice?

While it has been reported that MMP-2 expression does not compensate for MMP-9 deficiency in limb ischaemia or some models of arterial endothelial injury or ligation $[19,24,25]$, we (and others $[21,23,26]$ ) found that a loss of MMP-9 is at least partially compensated by an increase in MMP-2. This is possibly due to the considerable functional redundancy and genetic similarities found in the metalloproteinase family, and is akin to finding an increase in MMP-9 in MMP-2 null mice [27].

As we found in both control and MMP-9 null mice, MMP-2 and MMP-9 may be absent or present in very low levels in unused veins [14-16]. We did not find evidence of MMP-9 activation after engraftment (in line with some studies on grafts $[13,14]$ and ligated arteries $[19,21,24]$, but not other studies in rabbits $[8,17])$. This does not necessarily mean that there is no active MMP-9 being produced in the control animals. Active MMP-9 secreted by the graft may be lost from the vessel and swept away by the blood. Alternatively, the MMP may be activated once it leaves the graft, or at a different time from that examined (1 week). Both gelatinases are up-regulated within hours of vein preparation $[4,14,16]$ and remain elevated after arterialisation, with the amount of MMP-2 and MMP-9 proportional to the increased (that is, arterial) flow within the graft [8]. As MMP-2 is known to degrade gelatins faster than MMP-9 $[6,28]$ and is critical in reorganising collagen [13], MMP-2 may have a more dominant (and regulatory) effect than MMP-9 [8]. The up-regulation and activation of MMP-2 could also lead to a differentially elevated release of sequestered growth factors $[9,10,19]$ or the release and activation of other proteases $[6,25]$, resulting in changes in VSMC matrix deposition. These may account for the changes we observed in collagen content and remodelling; the presence of MMP-2 may compensate for the lack of MMP-9. However, the relationship between MMP-9 and MMP-2 remains to be elucidated.

It is known that VSMC adapt to injury (such as angioplasty) by altering their contractile and cytoskeletal ar- rangements, including $\alpha$-actin expression [29]. Such cytoskeletal changes have been directly linked to the activation of MMP-2 (and MMP-9) [30], possibly via proteases; a number of MMPs and fibrinolytic enzymes have been implicated $[4,6,23,30]$. Additionally, mechanical stretching (as occurs during arterialisation of the graft) is associated with elevated reactive oxygen species and increased MMP-2 mRNA, protein levels and activation, without changes in TIMP-1, TIMP-2 or MMP-14 (which are known to influence MMP-2 activity/activation) $[4,15$, 31]. The MMP-2 increase we observed may also be due to alterations in TIMP species or levels, or by increased induction by the elevated levels of the other (unidentified) proteases. However, while arterialisation of grafts from MMP-9 null mice may result in increased MMP-2, to show how this comes about would require further experiments in this model using an MMP-2 inhibitor.

These combined results confirm that the effects of MMP-9 in the vascular tree are ambiguous, and its role appears to be dependent on the vessel (for example, brachiocephalic artery compared with aorta or vein graft) and the type of injury (ligation compared with neointimal injury or models of aneurysm formation) $[19,24,26,32]$.

To summarise, in this study we found that a lack of MMP-9 did not affect early vein graft thrombosis or vessel wall thickening and cell density. However, there were significant changes in collagen content and vein graft remodelling, possibly due to elevated levels of MMP-2. However, the increase in the amount and activation of MMP-2 was not enough to fully compensate for a deficiency in MMP-9.

\section{Acknowledgments}

The authors thank Dr. Chris Rogers of the Bristol Heart Institute for her detailed advice concerning the statistical analyses, and Dr. Ray Bush for expert assistance with mouse breeding. They also thank Dr. Yanhua Hu of King's College London for valuable discussion about the animal model she originated. Aftab Gill supplied the ligated artery (positive control) samples. A.C.T. was the recipient of an Australian National Health and Medical Research Council Biomedical (CJ Martin) Overseas Fellowship (ID No. 252926). Additional support was obtained from the British Heart Foundation and the Medical Research Council. 


\section{References}

1 Motwani JG, Topol EJ: Aortocoronary saphenous vein graft disease: pathogenesis, predisposition, and prevention. Circulation 1998;97:916-931.

-2 Torsney E, Mayr U, Zou Y, Thompson WD, $\mathrm{Hu}$ Y, Xu Q: Thrombosis and neointima formation in vein grafts are inhibited by locally applied aspirin through endothelial protection. Circ Res 2004;94:1466-1473.

$\checkmark 3$ Thomas AC, Campbell JH: Timecourse of fibrin deposition and removal after arterial injury. Thromb Res 2003;109:65-69.

$\checkmark 4$ Newby AC: Dual role of matrix metalloproteinases (matrixins) in intimal thickening and atherosclerotic plaque rupture. Physiol Rev 2005;85:1-31.

5 Fitzgerald M, Hayward IP, Thomas AC, Campbell GR, Campbell JH: Matrix metalloproteinase can facilitate the heparanaseinduced promotion of phenotype change in vascular smooth muscle cells. Atherosclerosis 1999; 145:97-106.

$\checkmark 6$ Lijnen HR, van Hoef B, Lupu F, Moons L, Carmeliet P, Collen D: Function of the plasminogen/plasmin and matrix metalloproteinase systems after vascular injury in mice with targeted inactivation of fibrinolytic system genes. Arterioscler Thromb Vasc Biol 1998;18:1035-1045.

$\checkmark 7$ Morishige K, Shimokawa H, Matsumoto Y, Eto Y, Uwatoku T, Abe K, Sueishi K, Takeshita A: Overexpression of matrix metalloproteinase- 9 promotes intravascular thrombus formation in porcine coronary arteries in vivo. Cardiovasc Res 2003;57:572-585.

$\checkmark 8$ Berceli SA, Jiang Z, Klingman NV, Pfahnl CL, Abouhamze ZS, Frase CD, Schultz GS, Ozaki CK: Differential expression and activity of matrix metalloproteinases during flow-modulated vein graft remodeling. J Vasc Surg 2004;39:1084-1090.

9 Mott JD, Werb Z: Regulation of matrix biology by matrix metalloproteinases. Curr Opin Cell Biol 2004;16:558-564.

10 Lelongt B, Bengatta S, Delauche M, Lund LR, Werb Z, Ronco PM: Matrix metalloproteinase 9 protects mice from anti-glomerular basement membrane nephritis through its fibrinolytic activity. J Exp Med 2001;193: 793-802.

- 11 Vu TH, Shipley JM, Bergers G, Berger JE, Helms JA, Hanahan D, Shapiro SD, Senior RM, Werb Z: MMP-9/gelatinase B is a key regulator of growth plate angiogenesis and apoptosis of hypertrophic chondrocytes. Cell 1998;93:411-422.
12 Gordon S: Alternative activation of macrophages. Nat Rev Immunol 2003;3:23-35.

13 Berceli SA, Jiang Z, Klingman NV, Schultz GS, Keith OC: Early differential MMP-2 and -9 dynamics during flow-induced arterial and vein graft adaptations. J Surg Res 2006; 134:327-334.

14 George SJ, Zaltsman AB, Newby AC: Surgical preparative injury and neointima formation increase MMP-9 expression and MMP 2 activation in human saphenous vein Cardiovasc Res 1997;33:447-459.

15 Chesler NC, Ku DN, Galis ZS: Transmural pressure induces matrix-degrading activity in porcine arteries ex vivo. Am J Physiol Heart Circ Physiol 1999;277:H2002-H2009.

16 Sharony R, Pintucci G, Saunders PC, Grossi EA, Baumann FG, Galloway AC, Mignatti P: Matrix metalloproteinase expression in vein grafts: role of inflammatory mediators and extracellular signal-regulated kinases-1 and -2. Am J Physiol Heart Circ Physiol 2006; 290:H1651-H1659.

17 Wong AP, Nili N, Jackson ZS, Qiang B, Le ong-Poi H, Jaffe R, Raanani E, Connelly PW Sparkes JD, Strauss BH: Expansive remodeling in venous bypass grafts: novel implications for vein graft disease. Atherosclerosis 2008;196:580-589.

$18 \mathrm{Hu}$ Y, Baker AH, Zou Y, Newby AC, Xu Q Local gene transfer of tissue inhibitor of metalloproteinase- 2 influences vein graft remodeling in a mouse model. Arterioscler Thromb Vasc Biol 2001;21:1275-1280.

19 Cho A, Reidy MA: Matrix metalloproteinase- 9 is necessary for the regulation of smooth muscle cell replication and migration after arterial injury. Circ Res 2002;91: $845-851$.

20 Johnson C, Galis ZS: Matrix metalloproteinase -2 and -9 differentially regulate smooth muscle cell migration and cell-mediated collagen organization. Arterioscler Thromb Vasc Biol 2004;24:54-60.

21 Ikonomidis JS, Barbour JR, Amani Z, Stroud RE, Herron AR, McClister DM, Camens SE, Lindsey ML, Mukherjee R, Spinale FG: Effects of deletion of the matrix metalloproteinase 9 gene on development of murine thoracic aortic aneurysms. Circulation 2005; 112:I242-I248.

22 Zou Y, Dietrich H, Hu Y, Metzler B, Wick G $\mathrm{Xu} \mathrm{Q}$ : Mouse model of venous bypass graft arteriosclerosis. Am J Pathol 1998;153:13011310 .
23 Ducharme A, Frantz S, Aikawa M, Rabkin E, Lindsey M, Rohde LE, Schoen FJ, Kelly RA, Werb Z, Libby P, Lee RT: Targeted deletion of matrix metalloproteinase- 9 attenuates left ventricular enlargement and collagen accumulation after experimental myocardial infarction. J Clin Invest 2000;106:55-62.

24 Galis ZS, Johnson C, Godin D, Magid R, Shipley JM, Senior RM, Ivan E: Targeted disruption of the matrix metalloproteinase-9 gene impairs smooth muscle cell migration and geometrical arterial remodeling. Circ Res 2002;91:852-859.

25 Lessner SM, Martinson DE, Galis ZS: Compensatory vascular remodeling during atherosclerotic lesion growth depends on matrix metalloproteinase- 9 activity. Arterioscler Thromb Vasc Biol 2004;24:2123-2129.

26 Longo GM, Xiong W, Greiner TC, Zhao Y, Fiotti N, Baxter BT: Matrix metalloproteinases 2 and 9 work in concert to produce aortic aneurysms. J Clin Invest 2002;110:625632.

27 Esparza J, Kruse M, Lee J, Michaud M, Madri JA: MMP-2 null mice exhibit an early onset and severe experimental autoimmune encephalomyelitis due to an increase in MMP9 expression and activity. FASEB J 2004;18: 1682-1691.

28 Xia T, Akers K, Eisen AZ, Seltzer JL: Comparison of cleavage site specificity of gelatinases A and B using collagenous peptides. Biochim Biophys Acta 1996;1293:259-266.

29 Thomas AC, Campbell JH: Contractile and cytoskeletal proteins of smooth muscle cells in rat, rabbit, and human arteries. Tissue Cell 2000;32:249-256.

30 Rahat MA, Marom B, Bitterman H, WeissCerem L, Kinarty A, Lahat N: Hypoxia reduces the output of matrix metalloproteinase-9 (MMP-9) in monocytes by inhibiting its secretion and elevating membranal association. J Leukocyte Biol 2006;79:706-718.

-31 Grote K, Flach I, Luchtefeld M, Akin E, Holland SM, Drexler H, Schieffer B: Mechanical stretch enhances mRNA expression and proenzyme release of matrix metalloproteinase2 (MMP-2) via NAD(P)H oxidase-derived reactive oxygen species. Circ Res 2003;92: e80-e86.

>32 Johnson JL, George SJ, Newby AC, Jackson CL: Divergent effects of matrix metalloproteinases $3,7,9$, and 12 on atherosclerotic plaque stability in mouse brachiocephalic arteries. Proc Natl Acad Sci USA 2005;102: 15575-15580 